\title{
Somatosensory and Brainstem Auditory Evoked Potentials Assessed between 4 and 7 Days after Severe Stroke Onset Predict Unfavorable Outcome
}

\author{
Yan Zhang, ${ }^{1}$ Ying Ying Su, ${ }^{1}$ Shu Ying Xiao, ${ }^{2}$ and Yi Fei Liu ${ }^{1}$ \\ ${ }^{1}$ Department of Neurology, Xuanwu Hospital, Capital Medical University, Beijing 100053, China \\ ${ }^{2}$ Department of Neurology, Luhe Hospital, Capital Medical University, Beijing 100053, China
}

Correspondence should be addressed to Yan Zhang; zhangylq@sina.com

Received 8 August 2015; Revised 12 November 2015; Accepted 19 November 2015

Academic Editor: Erwin van Wegen

Copyright (C) 2015 Yan Zhang et al. This is an open access article distributed under the Creative Commons Attribution License, which permits unrestricted use, distribution, and reproduction in any medium, provided the original work is properly cited.

\begin{abstract}
Our objective was to explore the best predictive timing of short-latency somatosensory evoked potentials (SLSEP) and brainstem auditory evoked potentials (BAEP) for unfavorable outcomes in patients with early stage severe stroke. One hundred fifty-six patients with acute severe supratentorial stroke were monitored according to SLSEP, BAEP, and the Glasgow Coma Scale (GCS) at 1-3 days and 4-7 days after the onset of stroke. All patients were followed up for outcomes at 6 months after onset using the modified Rankin Scale (mRS), with a score of 5-6 considered unfavorable. The predictive values of SLSEP, BAEP, and the GCS at 1-3 days were compared with 4-7 days after onset. Our results show that, according to the analysis of prognostic authenticity, the predictive values of SLSEP and BAEP at 4-7 days after stroke onset improved when compared with the values at 1-3 days for unfavorable outcomes. Most of the patients with change of worsening evoked potentials from 1-3 days to 4-7 days after onset had unfavorable outcomes. In conclusion, SLSEP and BAEP assessed at 4-7 days after onset predicted unfavorable outcomes for acute severe stroke patients. The worsening values of SLSEP and BAEP between 1-3 days and 4-7 days also present a prognostic value.
\end{abstract}

\section{Introduction}

Evoked potentials (EPs) have been widely utilized to predict the outcome of patients with acute severe strokes. Although previous studies have reviewed various timings, that is, within 7 days, 10 to 15 days, 30 days, 10 weeks, and 3 months after stroke onset [1-6], precise timing at early stage remains unclear. Physicians often prefer earlier predictions on prognosis in order to improve treatment strategies. Previous studies have found that short-latency somatosensory evoked potentials (SLSEP) N20 and brainstem auditory evoked potentials (BAEP) wave $\mathrm{V}$ within 7 days after stroke were highly consistent with the outcomes of patients $[1,2,5,6]$. However, 7 days is a relatively long period. Additionally, patients' conditions may change due to brain edemas during the 7-day period after stroke, especially in severe stroke patients. If optimal evaluations can be determined within the 7-day period that accurately predicts outcomes, properly informed and earlier medical treatments can be planned, enabling the optimal use of resources. It is well known that brain edemas take place 3-4 days after stroke, increased intracranial pressure peaks at 4-7 days, and patients often worsen at 4-7 days [7]. We hypothesized that the SLSEP and BAEP could be used to predict more accurate outcomes at 4-7 days than at 1-3 days after the onset of a severe stroke. Accordingly, we conducted a prospective blinded study to test our hypothesis.

\section{Materials and Methods}

2.1. Patients. Patients with acute severe supratentorial stroke admitted to the neurointensive care unit (NICU) of Xuanwu Hospital of Capital Medical University between January 2008 and December 2013 were enrolled in the study. The inclusion criteria were the following: (1) age from 18 to 85 years; (2) 1 to 3 days after the onset of the acute severe supratentorial stroke; (3) Glasgow Coma Scale (GCS) [8] $\leq 12$; and (4) severe cerebral infarction or intracranial hemorrhage confirmed by 
computed tomography and/or magnetic resonance imaging, that is, cerebral infarction volume $\geq 66 \%$ of the middle cerebral artery (MCA) territory [9] and hematoma amount $\geq 25 \mathrm{~mL}$ [10]. The exclusion criteria were the following: (1) presence of severe skin edemas of the upper extremities, cervical or head area; (2) history of severe hearing problems; (3) history of previous stroke; (4) lesions in posterior circulation territory; (5) undergoing intravenous thrombolysis or mechanical thrombectomy therapy; or (6) death within 3 days after the onset. The following parameters were recorded: (1) demographics (age and gender) and (2) stroke presentation, including the baseline National Institutes of Health Stroke Scale (NIHSS) (1-3 days after stroke onset) and the etiology of the brain lesion (infarction or hemorrhage).

2.2. Clinical Assessments and Evoked Potentials Monitoring. With the permission of the local ethics committee and the consent of the patients' families, we performed the clinical assessments of GCS and monitored the EPs, including SLSEP and BAEP. The GCS and EPs were examined by two experienced neurologists, respectively, at 1-3 days and 47 days after stroke onset. The physician assessing the GCS was blinded to the EPs results. The physician performing the EPs was blinded to the clinical assessments. The EPs were recorded as described previously by Zhang et al. [11] on the electromyography/evoked potential machine (Nicolet Select, Nicolet, Madison, WI, USA) with Ag/AgCl-sintered electrodes.

2.3. Clinical Assessments and EPs Parameters. The GCS includes tests of eye opening (1-4 points), speech response (1-5 points), and motor response (1-6 points). The maximum total score is 15 points. A GCS score of 6-12 was defined as a favorable prognostic predictor, and a score of 3-5 was defined as an unfavorable prognostic predictor [12, 13]. The classification of the EPs was defined according to the responses of N20 of SLSEP and V of BAEP: Grade 1, bilaterally normal responses; Grade 2, unilaterally normal responses and pathological responses in the other lateral; Grade 3, bilaterally pathological responses; Grade 4, unilaterally normal responses and absence of responses in the other lateral; Grade 5, unilaterally pathological response and absence of responses in the other lateral; and Grade 6, bilateral absence of responses. Normal EPs limits were defined at 3 SD from the mean value using the normal data bank of our NICU. The unfavorable prognostic predictors of the EPs included any abnormality of responses, that is, Grade 2 to Grade 6, and bilateral absence of responses, that is, Grade 6 .

2.4. Outcome Evaluation. We assessed outcomes at 6 months because stroke patients may improve following rehabilitation training administered within 6 months after stroke onset. Patients were followed up at 6 months by two physicians who were blinded to the clinical assessments and the EPs results. The modified Rankin Scale (mRS) [14] was utilized to measure outcomes. A score of 0-4 was considered a favorable outcome, whereas a score of 5-6 was graded as an unfavorable one [15]. The optimal outcome achieved within 6 months after stroke was used for analysis.
2.5. Statistical Analysis. SPSS version 17.0 was used to analyze the data. The prognosis differences in baseline characteristics and different parameters were assessed with the MannWhitney test for continuous variables and Fisher's exact tests for the categorical variables. The authenticity predictions included sensitivity, specificity, positive predictive value (PPV), and negative predictive value (NPV) of the predictors, including GCS 3-5, parameters (N20 was abnormal and bilateral N20 was absent) of SLSEP, and parameters (wave $\mathrm{V}$ was abnormal and bilateral wave $\mathrm{V}$ was absent) of BAEP for unfavorable outcome. Exact $95 \%$ confidence intervals (CIs) were estimated using the binomial distribution. Positive likelihood ratios (LR+) with 95\% CIs were also analyzed. If any of the cells of the $2 \times 2$ table contained no observations, we added a value of 0.5 to each cell to calculate $L R+[16]$.

\section{Results}

3.1. Baseline Data. A total of 156 patients were enrolled of which 94 were men and 62 were women aged between 23 and 85 years ( $64 \pm 14$, on average). A total of 123 patients suffered from supratentorial infarction, and 33 patients suffered from cerebral hemispheric hemorrhage. Sixty-seven patients had favorable outcomes, while 89 patients had unfavorable outcomes (Table 1). A total of 111 patients survived.

\subsection{Prognostic Authenticity Analysis of Possible Predictors for} Unfavorable Outcomes at 1-3 Days after Stroke Onset (the First Time). SLSEP (any abnormality of N20 and bilateral absence of N20) and BAEP (bilateral absence of V) were statistically significant in different outcomes based on Fisher's exact test analysis $(P<0.05)$ at $1-3$ days after stroke onset (Table 2$)$. The prognostic authenticity analysis showed that the sensitivity of any abnormality of N20 (96.6\%, 95\% CI: 89.8\%-99.1\%) was the best among the clinical assessment of the GCS and EPs. The specificity of bilateral absence of N20 and of bilateral absence of $\mathrm{V}$ was the best (100\%, 95\% CI: 93.2\%-100\%). The PPV of bilateral absence of N20 (100\%, 95\% CI: 51.7\%-100\%) and of bilateral absence of V (100\%, 95\% CI: 65.5\%-100\%) was also the best. The NPV of any abnormality of N20 was relatively high (80.0\%, 95\% CI: 51.4\%-94.7\%) (Table 3).

\subsection{Prognostic Authenticity Analysis of Possible Predictors for} Unfavorable Outcomes at 4-7 Days after Stroke Onset (the Second Time). The GCS, SLSEP, and BAEP were all statistically significant in different outcomes based on Fisher's exact test analysis $(P<0.05)$ at $4-7$ days after stroke onset (Table 2$)$. The prognostic authenticity analysis showed that the sensitivity of any abnormality of N20 (100\%, 95\% CI: 94.8\%$100 \%$ ) was the best among the clinical assessment of GCS and EPs. The specificity of bilateral absence of N20 and of bilateral absence of $\mathrm{V}$ was the best (100\%, 95\% CI: $93.2 \%-$ $100 \%)$. The PPV of bilateral absence of N20 (100\%, 95\% CI: $89.8 \%-100 \%)$ and of bilateral absence of $\mathrm{V}(100 \%, 95 \% \mathrm{CI}$ : $87.4 \%-100 \%)$ was also the best. The NPV of any abnormality of N20 was the best (100\%, 95\% CI: 78.1\%-100\%). Furthermore, the bilateral absence of N20 showed the highest LR+ of 65.22 (95\% CI: 4.09-1040.76), which was superior to other 
TABLE 1: Baseline characteristics and the brain lesions of patients with different outcomes at 6 months after stroke.

\begin{tabular}{lcc}
\hline & $\begin{array}{c}\text { Unfavorable } \\
\text { outcome } \\
(\text { mRS 5-6) }\end{array}$ & $\begin{array}{c}\text { Favorable outcome } \\
\text { (mRS 1-4) }\end{array}$ \\
\hline $\begin{array}{l}\text { Age, median (IQR) } \\
\text { Gender }\end{array}$ & $70(62-76)$ & $60(47-69)$ \\
Male, $n(\%)$ & $52(55.3)$ & $42(44.7)$ \\
Female, $n(\%)$ & $37(59.7)$ & $25(40.3)$ \\
NIHSS baseline, median (IQR) & $28(24-32)$ & $27(22-34)$ \\
Hemisphere stroke & & $38(44.7)$ \\
Left, $n(\%)$ & $47(55.3)$ & $29(40.8)$ \\
Right, $n(\%)$ & $42(59.2)$ & 0.623 \\
Etiology of the brain lesion & & $50(40.7)$ \\
Infarction, $n(\%)$ & $73(59.3)$ & $17(51.5)$ \\
Hemorrhage, $n(\%)$ & $16(48.5)$ & $67(42.9)$ \\
Total, $n$ (\%) & $89(57.1)$ & 0.745 \\
\hline
\end{tabular}

NIHSS, National Institutes of Health Stroke Scale; IQR, interquartile range.

TABle 2: Prognostic predictors at 1-3 d and 4-7 d after stroke onset with different outcomes at 6 months after stroke.

\begin{tabular}{|c|c|c|c|}
\hline Prognostic predictors & $\begin{array}{c}\text { Unfavorable } \\
\text { outcome } \\
\text { (mRS 5-6) } \\
1-3 \mathrm{~d} / 4-7 \mathrm{~d} \\
n(\%)\end{array}$ & $\begin{array}{c}\text { Favorable outcome } \\
\text { (mRS 1-4) } \\
1-3 \mathrm{~d} / 4-7 \mathrm{~d} \\
n(\%)\end{array}$ & $\begin{array}{l}P \text { value } \\
1-3 \mathrm{~d} / 4-7 \mathrm{~d}\end{array}$ \\
\hline \multicolumn{4}{|l|}{ GCS } \\
\hline $3-5$ & $20(66.7) / 56(81.2)$ & $10(33.3) / 13(18.8)$ & \multirow{2}{*}{$0.306 /<0.001$} \\
\hline $6-12$ & $69(54.8) / 33(37.9)$ & $57(45.2) / 54(62.1)$ & \\
\hline \multicolumn{4}{|l|}{ SLSEP } \\
\hline Abnormality of N20 & $86(61.0) / 89(64.5)$ & $55(39.0) / 49(35.5)$ & \multirow{2}{*}{$0.004 /<0.001$} \\
\hline Normality of N20 & $3(20.0) / 0(0)$ & $12(80.0) / 18(100)$ & \\
\hline \multicolumn{4}{|l|}{ SLSEP } \\
\hline Bilateral absence of N20 & $6(100) / 43(100)$ & $0(0) / 0(0)$ & \multirow{2}{*}{$0.037 /<0.001$} \\
\hline Appearance of N20 & $83(55.3) / 46(40.7)$ & $67(44.7) / 67(59.3)$ & \\
\hline \multicolumn{4}{|l|}{ BAEP } \\
\hline Abnormality of V & $67(61.5) / 81(68.1)$ & $42(38.5) / 38(31.9)$ & \multirow{2}{*}{$0.113 /<0.001$} \\
\hline Normality of V & $22(46.8) / 8(21.6)$ & $25(53.2) / 29(78.4)$ & \\
\hline \multicolumn{4}{|l|}{ BAEP } \\
\hline Bilateral absence of $\mathrm{V}$ & $10(100) / 34(100)$ & $0(0) / 0(0)$ & \multirow{2}{*}{$0.005 /<0.001$} \\
\hline Appearance of & $79(54.1) / 55(45.1)$ & $67(45.9) / 67(54.9)$ & \\
\hline Total & 89 (57.1) & $67(42.9)$ & \\
\hline
\end{tabular}

predictors (Table 3). When compared with 1-3 days after onset, the prognostic authenticity of the GCS, SLSEP, and BAEP improved at 4-7 days.

3.4. Analysis of Dynamic Changes of EPs from 1-3 Days to 47 Days after Stroke Onset. From 1-3 days to 4-7 days after stroke onset, decreases were noticed with the GCS (from 6-12 to 3-5) in 103 patients; deteriorations were noticed with SLSEP N20 (upgrade, for example, from Grade 2 to Grade 5) in 74 patients with BAEP wave $\mathrm{V}$ (upgrade) in
62 patients. These worsening changes were all significant in the different outcomes $(P<0.05)$. Sixty-six of 74 patients $(89.2 \%)$ with worsening SLSEP and 60 of 62 patients $(96.8 \%)$ with worsening BAEP ultimately had unfavorable outcomes (Table 4).

\section{Discussion}

We found that SLSEP and BAEP can predict unfavorable outcomes of stroke patients more accurately when assessed at 
TABle 3: Prognostic authenticity of possible predictors for unfavorable outcomes at 1-3 d and 4-7 d after stroke onset.

\begin{tabular}{|c|c|c|c|c|c|}
\hline Prognostic predictors & $\begin{array}{l}\text { Sensitivity } \\
\%(95 \% \mathrm{CI}) \\
1-3 \mathrm{~d} / 4-7 \mathrm{~d}\end{array}$ & $\begin{array}{c}\text { Specificity } \\
\%(95 \% \mathrm{CI}) \\
1-3 \mathrm{~d} / 4-7 \mathrm{~d}\end{array}$ & $\begin{array}{c}\text { Positive predictive } \\
\text { value } \%(95 \% \mathrm{CI}) \\
1-3 \mathrm{~d} / 4-7 \mathrm{~d}\end{array}$ & $\begin{array}{c}\text { Negative predictive } \\
\text { value } \\
\%(95 \% \mathrm{CI}) \\
1-3 \mathrm{~d} / 4-7 \mathrm{~d}\end{array}$ & $\begin{array}{c}\text { Positive likelihood } \\
\text { ratios } \\
\%(95 \% \mathrm{CI}) \\
1-3 \mathrm{~d} / 4-7 \mathrm{~d} \\
\end{array}$ \\
\hline \multicolumn{6}{|l|}{ GCS } \\
\hline $3-5$ & $\begin{array}{l}22.5(14.6-32.8) / \\
62.9(52.0-72.7)\end{array}$ & $\begin{array}{l}85.1(73.8-92.2) / \\
80.6(68.8-88.9)\end{array}$ & $\begin{array}{l}66.7(47.1-82.1) / \\
81.2(69.6-89.2)\end{array}$ & $\begin{array}{c}45.2(36.4-54.3) / \\
62.1(51.0-72.1)\end{array}$ & $\begin{array}{l}1.51(0.76-3.00) / \\
3.24(1.94-5.42)\end{array}$ \\
\hline \multicolumn{6}{|l|}{ SLSEP } \\
\hline Abnormality of N20 & $\begin{array}{c}96.6(89.8-99.1) / \\
100(94.8-100)\end{array}$ & $\begin{array}{c}17.9(90.0-29.6) / \\
26.9(17.1-39.3)\end{array}$ & $\begin{array}{l}61.0(52.4-69.0) / \\
64.5(55.8-72.3)\end{array}$ & $\begin{array}{c}80.0(51.4-94.7) / \\
100(78.1-100)\end{array}$ & $\begin{array}{l}1.18(1.05-1.33) / \\
1.37(1.18-1.58)\end{array}$ \\
\hline Bilateral absence of N20 & $\begin{array}{l}6.7(2.8-14.6) / \\
48.3(37.7-59.1)\end{array}$ & $\begin{array}{c}100(93.2-100) / \\
100(93.2-100)\end{array}$ & $\begin{array}{l}100(51.7-100) / \\
100(89.8-100)\end{array}$ & $\begin{array}{l}44.7(36.6-53.0) / \\
59.3(49.6-68.3)\end{array}$ & $\begin{array}{c}9.10(0.52-160.13) / \\
65.22 \\
(4.09-1040.76)\end{array}$ \\
\hline \multicolumn{6}{|l|}{ BAEP } \\
\hline Abnormality of $\mathrm{V}$ & $\begin{array}{c}75.3(64.8-83.5) / \\
91.0(82.6-95.8)\end{array}$ & $\begin{array}{l}37.3(26.1-50.0) / \\
43.3(31.4-55.9)\end{array}$ & $\begin{array}{c}61.5(51.6-70.5) / \\
68.1(58.8-76.1)\end{array}$ & $\begin{array}{l}53.2(38.2-67.6) / \\
78.4(61.3-89.3)\end{array}$ & $\begin{array}{l}1.20(0.96-1.50) / \\
1.60(1.29-2.00)\end{array}$ \\
\hline Bilateral absence of $\mathrm{V}$ & $\begin{array}{c}11.2(5.8-20.1) / \\
38.2(28.3-49.2)\end{array}$ & $\begin{array}{l}100(93.2-100) / \\
100(93.2-100)\end{array}$ & $\begin{array}{c}100(65.5-100) / \\
100(87.4-100)\end{array}$ & $\begin{array}{l}45.9(37.7-54.3) / \\
54.9(45.7-63.9)\end{array}$ & $\begin{array}{l}15.17(0.91-255.14) / \\
51.57(3.22-826.44)\end{array}$ \\
\hline
\end{tabular}

GCS, Glasgow Coma Scale; SLSEP, short-latency somatosensory evoked potential; BAEP, brainstem auditory evoked potential.

TABLE 4: Analysis of dynamic changes of EPs from 1-3 days to 4-7 d after stroke onset.

\begin{tabular}{|c|c|c|c|c|c|c|c|c|}
\hline $\begin{array}{l}\text { Prognostic } \\
\text { predictors }\end{array}$ & $\begin{array}{c}\text { Unfavorable } \\
\text { outcome } \\
\text { (mRS 5-6) } \\
n(\%)\end{array}$ & $\begin{array}{c}\text { Favorable } \\
\text { outcome } \\
\text { (mRS 1-4) } \\
n(\%)\end{array}$ & $P$ value & $\begin{array}{l}\text { Sensitivity } \\
\%(95 \% \mathrm{CI})\end{array}$ & $\begin{array}{l}\text { Specificity } \\
\%(95 \% \text { CI) }\end{array}$ & $\begin{array}{c}\text { Positive } \\
\text { predictive } \\
\text { value } \\
\%(95 \% \mathrm{CI})\end{array}$ & $\begin{array}{c}\text { Negative } \\
\text { predictive } \\
\text { value } \\
\%(95 \% \mathrm{CI})\end{array}$ & $\begin{array}{c}\text { Positive } \\
\text { likelihood } \\
\text { ratios } \\
\%(95 \% \mathrm{CI})\end{array}$ \\
\hline \multicolumn{9}{|l|}{ GCS } \\
\hline $\begin{array}{l}\text { Worse (from } \\
6-12 \text { to } 3-5 \text { ) }\end{array}$ & $\begin{array}{c}65 \\
(63.1)\end{array}$ & $\begin{array}{c}38 \\
(36.9)\end{array}$ & 0.041 & $\begin{array}{c}73.0 \\
(62.4-81.6)\end{array}$ & $\begin{array}{c}26.9 \\
(16.0-41.3)\end{array}$ & $\begin{array}{c}63.1 \\
(53.0-72.2)\end{array}$ & $\begin{array}{c}36.8 \\
(22.3-54.0)\end{array}$ & $\begin{array}{c}1.00 \\
(0.81-1.23)\end{array}$ \\
\hline \multicolumn{9}{|l|}{ SLSEP } \\
\hline Worse (upgrade) & $\begin{array}{c}66 \\
(89.2)\end{array}$ & $\begin{array}{c}8 \\
(10.8)\end{array}$ & $<0.001$ & $\begin{array}{c}74.2 \\
(63.6-82.6)\end{array}$ & $\begin{array}{c}88.1 \\
(77.3-94.3)\end{array}$ & $\begin{array}{c}89.2 \\
(79.3-94.9)\end{array}$ & $\begin{array}{c}72.0 \\
(60.8-81.0)\end{array}$ & $\begin{array}{c}6.21 \\
(3.20-12.04)\end{array}$ \\
\hline \multicolumn{9}{|l|}{ BAEP } \\
\hline Worse (upgrade) & $\begin{array}{c}60 \\
(96.8) \\
\end{array}$ & $\begin{array}{c}2 \\
(3.2) \\
\end{array}$ & $<0.001$ & $\begin{array}{c}67.4 \\
(56.6-76.8) \\
\end{array}$ & $\begin{array}{c}97.0 \\
(88.7-99.5) \\
\end{array}$ & $\begin{array}{c}96.8 \\
(87.8-99.4) \\
\end{array}$ & $\begin{array}{c}69.1 \\
(58.7-78.0) \\
\end{array}$ & $\begin{array}{c}22.58 \\
(5.72-89.12) \\
\end{array}$ \\
\hline
\end{tabular}

GCS, Glasgow Coma Scale; SLSEP, short-latency somatosensory evoked potential; BAEP, brainstem auditory evoked potential; $95 \%$ CI, 95\% confidence intervals.

4-7 days after stroke onset than at 1-3 days. Brain edemas take place 3-4 days after stroke, and increased intracranial pressure peaks at 4-7 days [7]. Patients often worsen during this time period. The predictive timing of acute stroke assessments at 4-7 days after onset is believed to more accurately reflect brain function than assessments at 1-3 days. We also found that SLSEP and BAEP have better predictive accuracy for brain function than GCS.

The absence of N20 indicates an extensive injury of the cerebral cortex and therefore a poor outcome. From our data, the specificity and PPV of bilateral absence of N20 were both $100 \%$ within 7 days after stroke onset, which was best among predictors and as good as that of bilateral absence of $\mathrm{V}$ of BAEP. SLSEP N20 is generated from a large section of the cortex-subcortex area. After a large number of neurons and/ or axes are damaged, N20 will be completely absent. In prior studies, the bilateral loss of SLSEP component N20 in severe brain damage often implied a fatal prognosis in all adult patients (specificity $=93.3 \%$ and sensitivity $=59.3 \%$ ). Only a young child with predominant brainstem hemorrhagic contusion regained consciousness with mild-to-moderate resultant neurological deficits (Glasgow Outcome Scale 3-4) during long-term follow-up of 4 years $[17,18]$. We observed that although bilateral N20 emerged in some cases, any N20 abnormality also indicated the possibility of poor outcomes. The sensitivity and NPV of either lateral abnormality of N20 were $100 \%$ for unfavorable prognosis.

The bilateral absence of wave $\mathrm{V}$ was also a reliable predictor of poor outcomes, especially for bilateral abnormalities. In the present study, the specificity and PPV of the bilateral absence of $\mathrm{V}$ were both $100 \%$ within 7 days after stroke onset, which was also best among predictors. This is consistent with Liu's findings about patients with putaminal hemorrhage [19]. The BAEP wave $\mathrm{V}$ is a robust indicator of brainstem function. 
If any primary or secondary supratentorial disease deteriorates and impairs the function of brainstem, the $\mathrm{V}$ of BAEP originating from the inferior colliculus will first change [6]. Therefore, BAEP wave $\mathrm{V}$ is the most reliable predictor for unfavorable outcome of supratentorial stroke.

The worsening of the SLSEP and BAEP between 1-3 days and 4-7 days also provided a prognostic value. Our dynamic assessments found that the GCS, SLSEP, and BAEP worsened in some patients within 7 days after stroke. For more than one-third of 156 patients, the SLSEP and BAEP worsened, and most of these affected patients (89.2-96.8\%) had poor outcomes. This indicated that worsening SLSEP and BAEP might be a reliable predictor of the degree of irreversible deterioration. Additionally, the reliability increased with serial recordings. In conclusion, patients with uncertain prognoses 1-3 days after stroke should be further evaluated, especially for the SLSEP and BAEP, to discover the brain function changes for proper and timely clinical decisions [20].

\section{Conclusions}

From this study, 4-7 days after stroke onset was a better timing for predicting outcome, and the SLSEP N20 and BAEP wave $\mathrm{V}$ were the most reliable predictors for patients with severe supratentorial strokes. Predictors at 1-3 days after stroke can provide reference values; the worsening of the SLSEP and BAEP between 1-3 days and 4-7 days could provide a strong prognostic value. This study was limited by the small sample size and the use of patients from a single center and could be further expanded by conducting a prospective multicenter study.

\section{Conflict of Interests}

The authors declare that they have no conflict of interests related to this work.

\section{Acknowledgment}

This study is supported by National Natural Science Foundation of China (81441037).

\section{References}

[1] L. Burghaus, W.-C. Liu, C. Dohmen, B. Bosche, and W. F. Haupt, "Evoked potentials in acute ischemic stroke within the first $24 \mathrm{~h}$ : possible predictor of a malignant course," Neurocritical Care, vol. 9, no. 1, pp. 13-16, 2008.

[2] W. F. Haupt, G. Pawlik, and A. Thiel, "Initial and serial evoked potentials in cerebrovascular critical care patients," Journal of Clinical Neurophysiology, vol. 23, no. 5, pp. 389-394, 2006.

[3] Y. Péréon, P. Aubertin, and P. Guihéneuc, "Prognostic significance of electrophysiological investigations in stroke patients: somatosensory and motor evoked potentials and sympathetic skin response," Neurophysiologie Clinique, vol. 25, no. 3, pp. 146157, 1995.

[4] P. Tzvetanov and R. T. Rousseff, "Predictive value of medianSSEP in early phase of stroke: a comparison in supratentorial infarction and hemorrhage," Clinical Neurology and Neurosurgery, vol. 107, no. 6, pp. 475-481, 2005.

[5] Y. Y. Su, S. Y. Xiao, W. F. Haupt et al., "Parameters and grading of evoked potentials: prediction of unfavorable outcome in patients with severe stroke," Journal of Clinical Neurophysiology, vol. 27, no. 1, pp. 25-29, 2010.

[6] L. Burghaus, W.-C. Liu, C. Dohmen, W. F. Haupt, G. R. Fink, and C. Eggers, "Prognostic value of electroencephalography and evoked potentials in the early course of malignant middle cerebral artery infarction," Neurological Sciences, vol. 34, no. 5, pp. 671-678, 2013.

[7] E. F. M. Wijdicks, K. N. Sheth, B. S. Carter et al., "Recommendations for the management of cerebral and cerebellar infarction with swelling: a statement for healthcare professionals from the American Heart Association/American Stroke Association," Stroke, vol. 45, no. 4, pp. 1222-1238, 2014.

[8] G. Teasdale and B. Jennett, "Assessment of coma and impaired consciousness. A practical scale," The Lancet, vol. 304, no. 7872, pp. 81-84, 1974.

[9] J. Hofmeijer, A. Algra, L. J. Kappelle, and H. B. van der Worp, "Predictors of life-threatening brain edema in middle cerebral artery infarction," Cerebrovascular Diseases, vol. 25, no. 1-2, pp. 176-184, 2008.

[10] S. A. Mayer, C. E. Thomas, and B. E. Diamond, "Asymmetry of intracranial hemodynamics as an indicator of mass effect in acute intracerebral hemorrhage. A transcranial Doppler study," Stroke, vol. 27, no. 10, pp. 1788-1792, 1996.

[11] Y. Zhang, Y. Y. Su, W. F. Haupt et al., "Application of electrophysiologic techniques in poor outcome prediction among patients with severe focal and diffuse ischemic brain injury," Journal of Clinical Neurophysiology, vol. 28, no. 5, pp. 497-503, 2011.

[12] D. Agrawal, "Endovascular treatment for poorest-grade subarachnoid hemorrhage in the acute stage: has the outcome been improved?" Neurosurgery, vol. 52, no. 2, pp. 481-482, 2003.

[13] J. Inamasu, Y. Nakamura, R. Saito et al., "Endovascular treatment for poorest-grade subarachnoid hemorrhage in the acute stage: has the outcome been improved?" Neurosurgery, vol. 50, no. 6, pp. 1199-1206, 2002.

[14] G. Sulter, C. Steen, and J. De Keyser, "Use of the Barthel index and modified Rankin scale in acute stroke trials," Stroke, vol. 30, no. 8, pp. $1538-1541,1999$.

[15] J. M. Ferro, I. Crassard, J. M. Coutinho et al., "Decompressive surgery in cerebrovenous thrombosis: a multicenter registry and a systematic review of individual patient data," Stroke, vol. 42, no. 10, pp. 2825-2831, 2011.

[16] E. G. J. Zandbergen, A. Hijdra, J. H. T. M. Koelman et al., "Prediction of poor outcome within the first 3 days of postanoxic coma," Neurology, vol. 66, no. 1, pp. 62-68, 2006.

[17] B. Fierro, V. La Bua, M. Oliveri, O. Daniele, and F. Brighina, "Prognostic value of somatosensory evoked potentials in stroke," Electromyography and Clinical Neurophysiology, vol. 39, no. 3, pp. 155-160, 1999.

[18] B. Pohlmann-Eden, K. Dingethal, H.-J. Bender, and W. Koelfen, "How reliable is the predictive value of SEP (somatosensory evoked potentials) patterns in severe brain damage with special regard to the bilateral loss of cortical responses?" Intensive Care Medicine, vol. 23, no. 3, pp. 301-308, 1997. 
[19] C.-W. Liu, N.-S. Chu, and S.-J. Ryu, "CT, somatosensory and brainstem auditory evoked potentials in the early prediction of functional outcome in putaminal hemorrhage," Acta Neurologica Scandinavica, vol. 84, no. 1, pp. 28-32, 1991.

[20] W. F. Haupt and G. Pawlik, "Contribution of initial mediannerve somatosensory evoked potentials and brainstem auditory evoked potentials to prediction of clinical outcome in cerebrovascular critical care patients: a statistical evaluation," Journal of Clinical Neurophysiology, vol. 15, no. 2, pp. 154-158, 1998. 


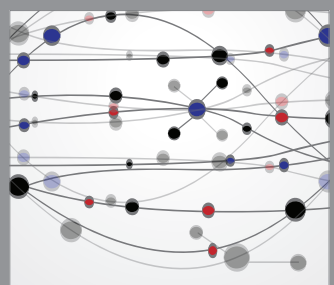

The Scientific World Journal
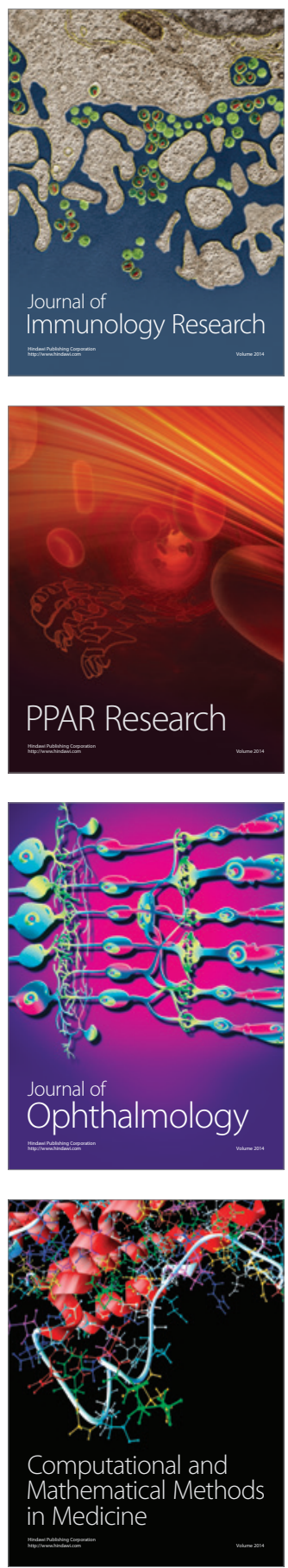

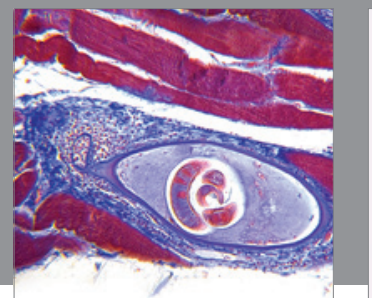

Gastroenterology

Research and Practice
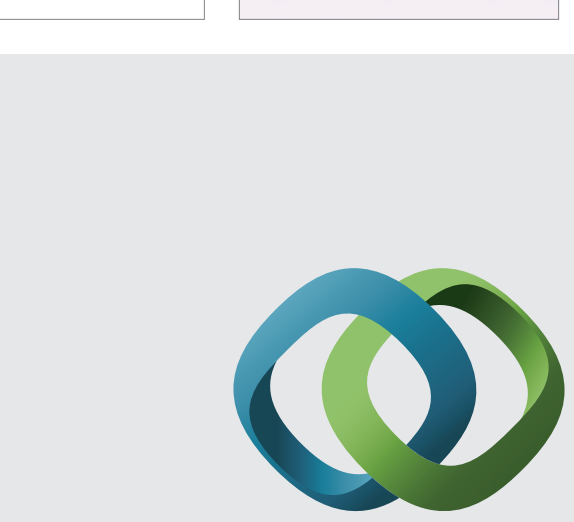

\section{Hindawi}

Submit your manuscripts at

http://www.hindawi.com
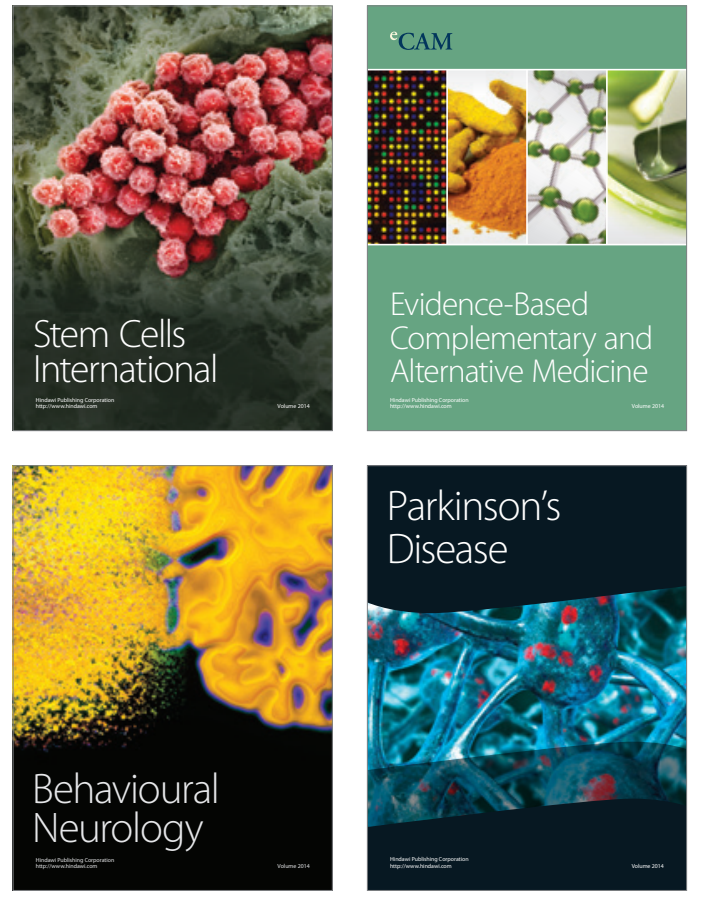
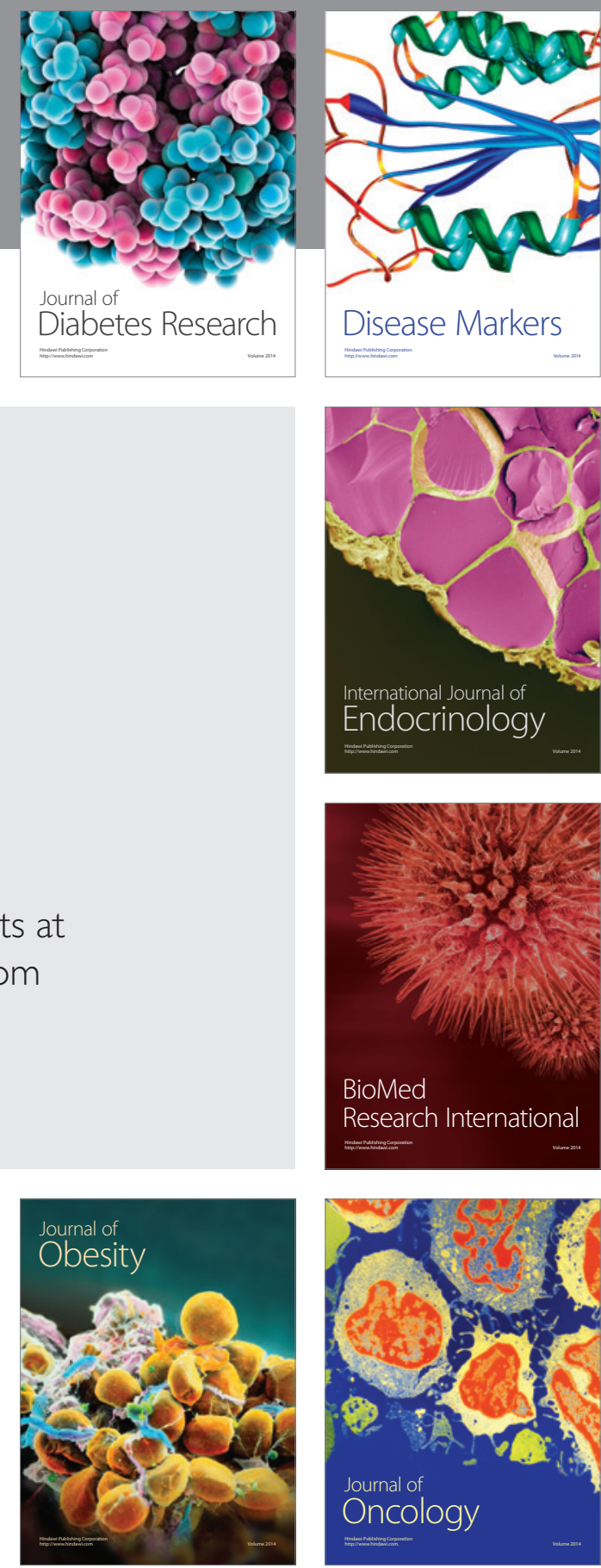

Disease Markers
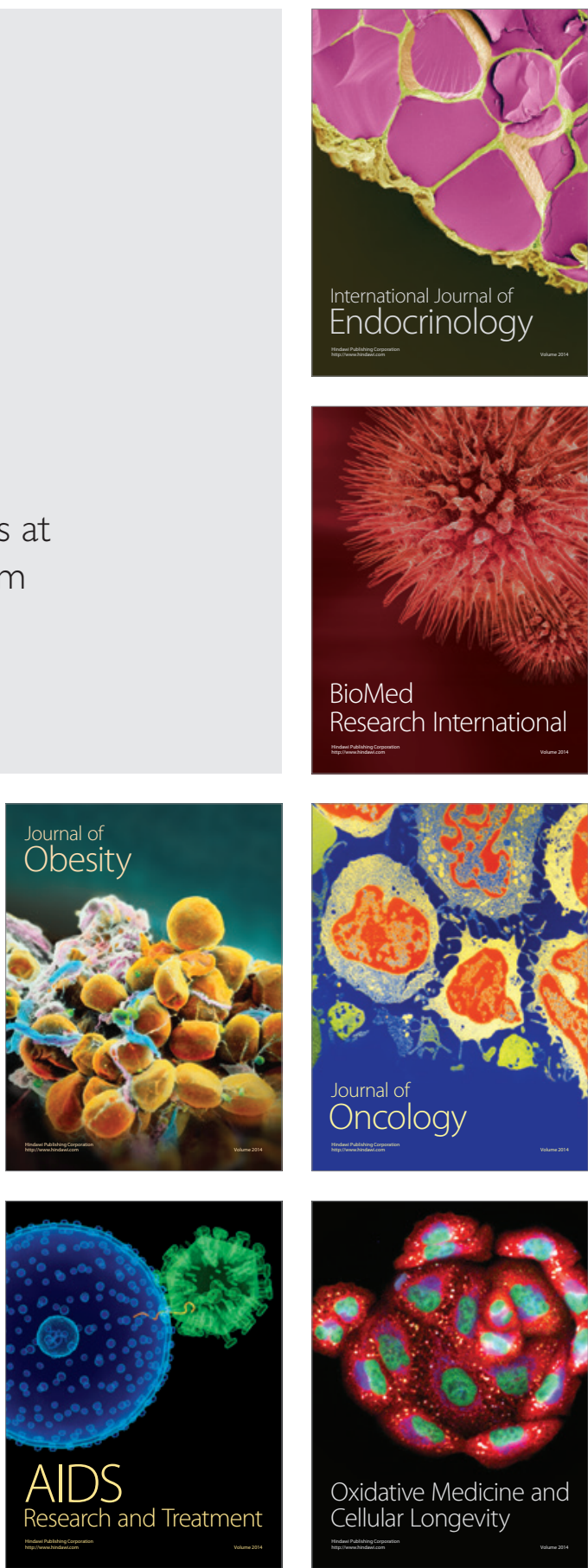